\title{
Allergieauslöser Arzt
}

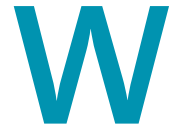

ir Allergologen sind Kummer gewohnt: „Unsere“ Erkrankungen nehmen so schnell zu, dass gerne von einer „Epidemie“ gesprochen wird. Dennoch müssen wir uns zweierlei eingestehen: Erstens sind Allergien immer noch nicht so häufig, wie der unkritische Umgang mit diesem Begriff außerhalb der "Szene“ es nahe legt. Zweitens, und damit wenden wir unseren Blick dem Thema der nächsten beiden Ausgaben des Allergo Journals zu, ist eine Ursache für Allergien - der Arzt!

Arzneimittel spielen als Ursache für allergische Reaktionen eine besonders herausfordernde Rolle. Oft manifestieren sie sich an Haut und Schleimhäuten. Wiederum dürfen wir nicht vergessen, dass trotz der relativ hohen Inzidenz echter Arzneimittelallergien die nicht allergischen Reaktionen noch häufiger sind. Viele von Ihnen wissen aus

„Kutane Arzneimittelreaktionen sind Stoff für mehr als ein Themenheft des Allergo

Journals. Wir haben uns bemüht, auch für gestandene Allergologen spannende Aspekte auszuwählen!“ eigener konsiliarischer Tätigkeit, dass sich hinter Exanthemen beileibe nicht immer eine Arzneimittelreaktion verbergen muss; die Differenzialdiagnose ist nicht selten schwierig. Und wenn der Patient dann auch noch ein Antibiotikum, ein

Diuretikum und ein Antidepressivum bekommt, zusätzlich ein Homöopathikum einnimmt ... Ach ja, es muss natürlich auch gar kein Exanthem sein!

Kutane Arzneimittelreaktionen sind Stoff für mehr als ein Themenheft des Allergo Journals. Mühelos ließen sich zwei (oder mehr) Hefte füllen, so dass wir sehr selektieren mussten. Dabei haben wir uns bemüht, einige auch für gestandene Allergologen - und gerade auch für Nicht-Dermatologen - spannende Aspekte auszuwählen: Quasi als Propädeutik vermittelt Prof. Dr. Hans F. Merk eingangs Aktuelles zu Klinik, Epidemiologie und Pathogenese, bevor in den nachfolgenden Beiträgen aus jeweils aktuellem Anlass verschiedene Substanzgrup-

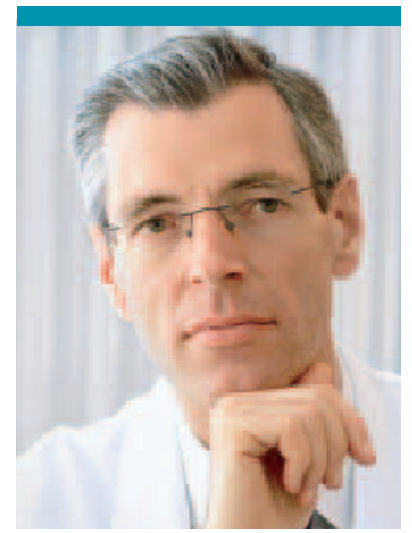

Prof. Dr. Wolf-Henning Boehncke, Zentrum der Dermatologie und Venerologie, Johann-Wolfgang-GoetheUniversität, Frankfurt/Main

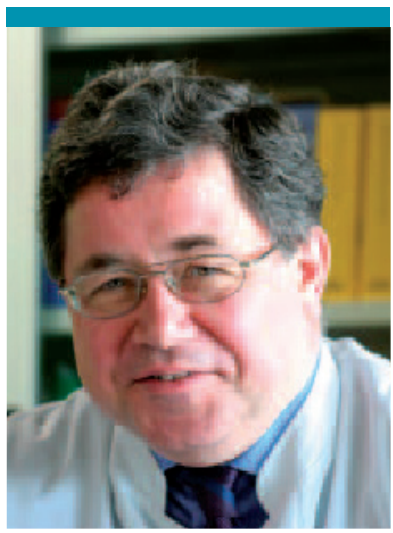

Prof. Dr. Hans F. Merk, Klinik für Dermatologie und Allergologie, Universitätsklinikum der RWTH Aachen pen thematisiert werden. Biologics haben sich schon heute einen festen Platz in der Therapie mehrerer wichtiger entzündlicher oder maligner Erkrankungen gesichert - und das ist erst der Anfang. Der Beitrag von Dr. Rotraut Mössner und Prof. Dr. Kristian Reich vermittelt einen Überblick über die vielgestaltigen Reaktionen auf diese Proteine. Erstaunlich wenig war lange Zeit bekannt zu Allergien auf „Klassiker“ wie Heparine. Das ändert sich derzeit nachhaltig, wie Priv.-Doz. Dr. Axel Trautmann berichtet. Selbst die gute alte „AspirinIntoleranz" ... ups, das kommt ja erst im nächsten Heft!

Viel Spaß beim Lesen. Und: Wenn diese Thematik Sie anspricht, dann freuen Sie sich schon auf die nächste Ausgabe des Allergo Journals!
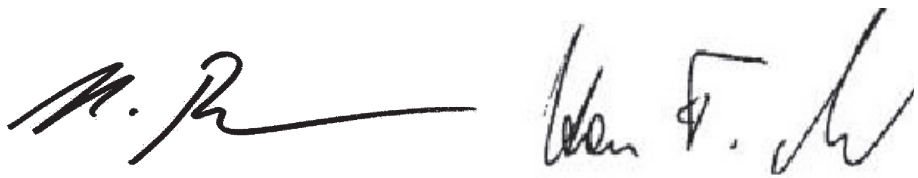

Prof. Dr. Wolf-Henning Boehncke Prof. Dr. Hans F. Merk 